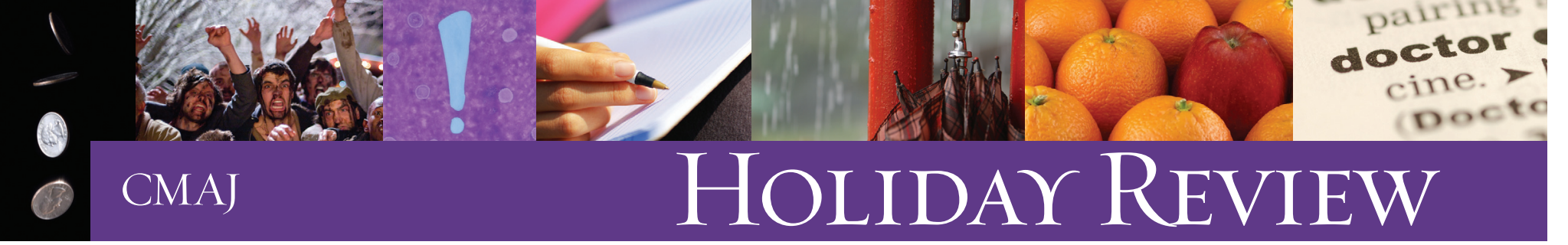

ESSAY

\title{
Writing about colleagues
}

$\mathrm{M}$ any doctors like to write about their experiences in medicine, myself included. In part, this is because people often write about what they know best, or in the case of physicians, the only thing they know anything about at all (medicine) and the only people they really care about even slightly (themselves). Physicians may also have an unconscious motive for writing, such as the desire to be paid a few hundred dollars extra to get a spiffy new pair of shoes or an hour at the spa. Actually, that may be a conscious motive, as my analyst pointed out to me last week when I was telling him about this article I was writing.

I started seeing Dr. Janus because Hollywood led me to believe it would be a cool thing to do. So far, it has been disappointing. "Come now, Lara," he said patiently, "I refuse to believe that your creative impetus derives solely from a shallow materialism investing your ego impulses in retrogressive, compensatory gratification. When I read some of your articles, I sense a thinly veiled hostility directed toward colleagues, who invariably embody the manifest stereotypical characteristics of their specialties, and I wonder if what we are seeing is an act of aggression, an effort to preserve narcissistic mastery in the face of vestigial sibling rivalry and subsumed oedipal conflict."

I looked up at the ceiling (which has the most appallingly tacky light fixture I have seen outside a reality TV show) and reflected that the lady analyst on the Sopranos was really much nicer than Dr. Janus, not to mention a whole lot easier to understand.

Nonetheless, he did get me thinking about the possible motivations one might have, besides money, for writing about colleagues. These include:

1. Flattery. If properly done, writing really nice things about colleagues can get you free drinks at the department holiday party.

$\infty$ 2. Seduction. Writing really, really nice things will get you those drinks in someone else's apartment after the holiday party wraps up. Or so I'm told.

3. Self-aggrandizement. I was going to say that this is only a problem if the physician-writer is a surgeon, but then I recalled something Dr. Janus said about manifest stereotypical bodies, so perhaps I'll let it pass. 
at least 30 minutes or so thinking about the subject with an analyst who, regrettably, looks nothing like Richard Gere in Final Analysis. Not that I went into analysis thinking he would, of course.

1. Don't write about real people, or if you do, combine three or four real people together to create a composite character. Like Dr. Janus except nice, like the Sopranos lady, and better looking.

2. Don't assume that just because you never bother to read anything in your field, nobody else does either. It's amazing how many people read journals and medical trade publications, especially the issue where you admit to having a crush on your immediate supervisor.

3. Don't write nasty things about colleagues who also write about colleagues on a regular basis. I once got into a prolonged battle with... Wait, scratch that.

Other authors will likely wish to further elucidate these points and add more, which I would encourage because it means they'll cite me, which is kind of cool when it (rarely) happens. If any of these authors wish to contact me, I would urge them to do so. I love collaborating with new colleagues, and who knows, perhaps they'll find themselves in print some day as a particularly charming facet of Dr. Janus's personality. If so, I hope I get invited over for a lime daiquiri.

\section{Lara Hazelton MD}

Psychiatrist

Halifax, NS 